\title{
The profession of nutrition-an historical perspective
}

\section{By J. P. W. Rivers, Department of Human Nutrition, London School of Hygiene and Tropical Medicine, Keppel Street, London WCI}

The dispassionate objectivity of scientists is a myth. No scientist is simply involved in the single-minded pursuit of truth, he is also engaged in the passionate pursuit of research grants and professional success. Nutritionists may wish to attack malnutrition, but they also wish to earn their living in ways they find congenial. Although many people are killed by malnutrition each year, an increasing number of us are kept alive by it.

To discuss research strategies without, therefore, discussing the researcher, is to omit a crucial element from the debate. And if we think of the researcher we must be aware that, not only are career structures for nutritionists affected by the research strategies we adopt, but the existence of those careers will, to a greater or lesser extent, shape the strategy that the profession chooses. So we cannot consider the future of the science of nutrition without considering the nature of the profession as well.

Members of the Nutrition Society commonly refer to themselves as 'professional nutritionists'. It is a significant phrase. It is used not merely as a genteel synonym for 'trade' as in 'professional hairdressers', but because it reflects the desire of the nutritionist to be considered alongside the classic professions of the church, the law and medicine.

There is no formal definition of the word profession, but it is evident that what are regarded as the professions share at least two attributes in common. First, they have a professional body which regulates standards and methods of entry, defines legitimate activities and defends its members against the predation of outsiders. Second, they have a sense of their importance, a sense accepted by the public at large, with whom they exist in a consultant-client relationship.

Judged by these standards nutrition is moving inexorably towards professional status. The Nutrition Society is not yet a full professional body, but as its history (Copping, 1978), constitution and activities make clear, it has shown an increasing tendency to professionalize throughout its existence. It is not merely that Nutrition Society members are quick to defend their 'expertise' against the medical profession. The policies of the Society have increasingly led to its taking on a professional role, the latest aspect being the decision of Council that applicants for membership should be known to Council or should submit a brief account of their interests in nutrition and reasons for seeking membership. This is not the action of a body wishing to disseminate information to anyone interested in the field, it is the action of a society concerned to maintain standards among its members.

These professional manifestations are, however, secondary to the crucial attribute of a profession, its sense of a consultant-client relationship. From the early twentieth century onwards, the nutritional literature is permeated with this 
sense. Nutritional science, which meant, at the time, almost solely the metabolic side of the subject, did not have the same criteria for success as, for example, astrophysics. Nutrition did not use elegance, coherence or predictive power as the test of a theory; the criterion was, notionally at least, a utilitarian one. Nutrition, like medicine, sought its primary justification in the fact that it was delivering health. The accolades of success within the profession have not gone to those whose work was intellectually exciting but to those supposed to have achieved significant advances in health. That is why human nutrition is funded by the Medical Research Council and not the Science Research Council. But although health has been the nominal goal of nutritional science, little attempt has been made to justify the belief that it has made a significant contribution to this end. Critical study shows it to have had minimal impact, and suggests that the professionalization of nutritional science has made it typical of what Illich (1977) has called 'disabling' professions, the dominance of which meant: "people had 'problems', experts had 'solutions' and scientists measured imponderables such as 'abilities' and 'needs'."

This is not to suggest that nutrition has not made major scientific advances, nor that those advances may not possibly be of some use at some future time. It is merely to suggest that scientific nutrition has not led to the improvement in nutritional status that it promised. If the criterion for the success of an applied science is utilitarian, its 'rightness' or 'wrongness' is irrelevant, and indeed an advance in scientific understanding may reduce its utility.

For example, in the nineteenth century Public Health reformers, led by Edwin Chadwick, acting on the theory that diseases were due to miasmas, inaugurated a public health programme which did much to reduce, not merely squalor and misery, but morbidity and mortality. Their campaign against filth achieved the right results but for the wrong reasons. (Singer \& Underwood, 1966.)

Moreover, when the germ theory of disease arose, it actually began to set the campaign back. Lister's antiseptic spray was vehemently opposed by both Florence Nightingale and Sir James Simpson on the grounds that it distracted attention from dirt. Ultimately the germ theory has been accepted as correct, but analysis of mortality statistics for the nineteenth century suggest that unlike the miasmatist theory it can claim little or no decline in mortality. (McKeown \& Lowe, 1966.)

This is an example the nutritionist should keep in mind, for it has analogues in the growth of our own subject. In IgII the newly formed Medical Research Committee designated rickets a priority area, and its subsequent support of both Sir Edward Mellanby and Dame Harriette Chick resulted in a massive yield of scientific information. But did it, as it was intended to, lead to a reduction in rickets? The best information on the extent of rickets in the nineteenth and twentieth centuries are the mortality records of the Registrar-General, since rickets has been accepted as an official cause of death since the nineteenth century. The results (Fig. I) show that mortality from rickets was on the decline 30 years before Mellanby or Chick did their work. 


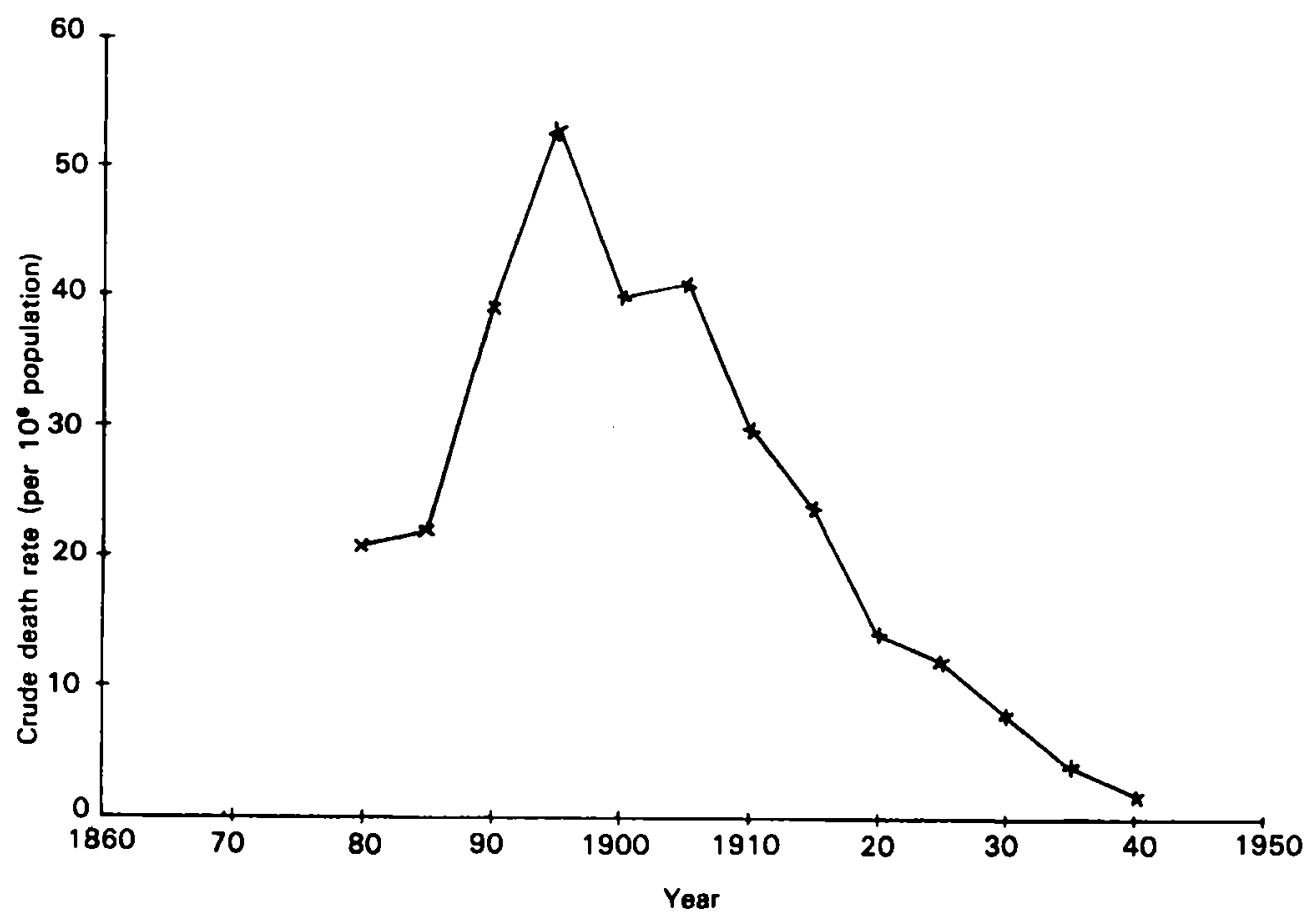

Fig. 1. Rickets and osteomalacia mortality (1880-1940) values taken from the records of the Registrar-General.

It may be argued, of course, that rickets is not a real cause of death, and that the information only reflects the curiously fickle nature of medical fashion. Conversely it can be equally argued that inasmuch as they reflect the prevalence of rickets in dead children, the results indicate that the disease itself may have been on the decline well before a scientific treatment was developed. Certainly exactly similar results exist for pellagra deaths in the USA and beriberi deaths in Japan, rates for both of which were declining years before their metabolic cause was discovered. In neither case can scientific advances in the understanding of the aetiology of these diseases be convincingly linked to declining mortality. (DeMaeyer \& Bengoa, I97 I.)

Moreover, if death rate records are prone to medical fashion so are clinical surveys of morbidity from rickets which have the added problems of bias due to over-zealous examiners and poor sample design. Many of those who reported on the disease were, of course, those who were campaigning against rickets and all that it represented. Such results must be treated with caution.

However, within their limits both morbidity and mortality figures tell a similar tale. They suggest that rickets was a disease of poor children in industrial towns which was declining with increasing affluence long before Mellanby started his work. At best, the practical result of the vitamin $D$ work has been a simple clinical cure, against which must be weighed the cases of idiopathic hypercalcaemia 
attributed to widespread overfortification with vitamin D. At worst, its result was the distraction of the public from the real cause of the disease-poverty.

These remarks might seem an unduly harsh critique on metabolic reductionism but they can be justified in the light of the involvement of the nutrition profession in three crucial practical areas in the twentieth century: the debate about poverty, ignorance and malnutrition, the wartime food policy in the UK and the post war involvement with nutrition and developing countries.

\section{Pozerty and ignorance as causes of malnutrition}

One of the inevitable sequelae of the classification of foods by their nutrient content was that different foods had different properties attributed to them. In the eighteenth century food was an homogenous whole, and an inadequate diet was seen simply as the result of poverty. Not much change occurred in the nineteenth century, for although the discovery of protein and the consequent division of foods into farinaceous and albuminous made quality as well as quantity an important dietary attribute, its practical effect was to increase the cost of what was regarded as a necessary diet and to stress further the effects of poverty. Throughout this period the cost of subsistence was regarded as the major determinant of nutritional status. (Rivers, 1978).

The discovery of the vitamins changed all that-nutritionists no longer considered merely how much food was needed but also what sort of diet was best. They became grossly over-enthusiastic about dietary quality and malnutrition was increasingly seen, not as an attribute of poverty, but a reflection of ignorance.

A clear example of this process can be seen in the debate on malnutrition in the United Kingdom that took place during the 1930s. On the one hand Boyd Orr (1935) showed clearly that malnutrition (defined as dietary inadequacy) increased as income fell, and that diets consumed became inadequate when food expenditure fell below $f_{0} \cdot 40 /$ person per week. Yet on the other hand, the professional view, as reflected by the British Medical Association was that, given wisdom, a nutritious diet could be constructed for fo.27/person per week, (BMA, 1933; BMA, 1939). Thus malnutrition at or above a level of food expenditure of $60.27 /$ week was regarded as the result of ignorance.

The BMA view prevailed. Despite the fact that their proposed diets were unpalatable and neglected all that was known about food habits in the UK, it was their concept of a theoretical minimal diet, and not Boyd Orr's idea of a practical level that reflected actual food habits, that became the basis for the budget on which post war national assistance and later supplementary benefits were based, (Woolf, 1946; Walker \& Church, 1978). Moreover, it is this view that is reflected in the continuing nutrition education programmes that seek to teach the poor how to manage. The notion that the specific handicap of poverty is an ignorance about nutrition rather than a lack of enough money to purchase a reasonable diet is a distasteful one. It is the direct product of the concept of dietary quality, and it fluorished in the hothouse atmosphere of 'protective foods' which the vitamin researchers generated with enthusiasm. Though the enthusiasm for vitamins is on 
the decline, nutritionists have yet seriously to reconsider their views on educations that derived from it.

\section{Nutrition policy in the Second World War}

So far the blame laid at the door of scientific nutrition has been indirect. The growth of the idea of nutritional ignorance might be unfortunate but it can hardly be blamed directly upon the research workers in nutrition. When the history of food policy in the Second World War is considered however, the utilitarian value of their nutrition research is put directly to the test. The nutrition profession prides itself on the fact that there was, in the United Kingdom, a scientific food and rationing policy between 1940 and 1945 , and it is commonly regarded as the fruition of scientific nutrition, in which scientific policies led to a clear improvement in the health of the nation (James, 1978).

These modern statements, the reiteration of euphoric post war ones, have remained unchallenged. However, if in fact the health of the nation did improve as a result of such nutrition intervention it is an important model for our activities elsewhere and deserves a more critical evaluation. Indicators of nutritional status seem to show an improvement during the war, but this alone is no proof of the effectiveness of wartime food policy. Many of them appear to have shown the same improvement during the 19308 when malnutrition was thought to be at epidemic proportions. For example, the decline in infant mortality is just a continuation of the trend observed throughout the century, and in fact the value for 1945 is precisely what it would have been if the 19303 rate of improvement is extrapolated (BMA, I950). Moreover, growth of children improved consistently throughout the 1930s (Baker et al. 1977) and it is not surprising that it continued to improve in the I940s with full employment. Most wartime clinical surveys of nutritional status were too poorly designed to show any changes. The best designed show no exceptional change in wartime.

Two clear changes can be seen: tooth decay rates fell, and deaths in middle-aged men were reduced. But scientific food policy can claim no credit for either of these changes. The Chief Medical Officer at the Ministry of Health dismissed the role of restricted wartime sugar supplies in reducing tooth decay and claimed it instead as a triumph of calcium and vitamin D fortification (Magee, 1946). He ignored the fact that the same fall had occurred during the First World War (BMA, I950) when, according to the conventional wisdom, vitamin $\mathrm{D}$ status was at its lowest.

The reduction in deaths in middle-aged men is unlikely to be due to a reduction in malnutrition amongst them. Retrospectively it is usually attributed to a reduction in the incidence of degeneration disease. However, such arguments must be viewed with caution. The reported drop in death rates from cardiovascular disease and diabetes mellitus may well have been coding artefacts - the $5^{\text {th }}$ Revision to the International Statistical Classification of Disease was made in 1939 and resulted in lower rates for these diseases - diabetes mellitus is reduced by $32.6 \%$ and arteriosclerosis by $61.5 \%$ if the 1939 death rates are calculated by the $5^{\text {th }}$ rather than the $4^{\text {th }}$ revision (Campbell, 1965). Even the 
reduction in mortality could be attributed to reduced dairy fat intakes or increased fibre intake from bread, these were coincidental changes in food habits during the war, to which the nutrition profession was, at that time, opposed.

Nutritionists at the time, regarded milk and butter as wholly good and advocated wholemeal bread only because of its vitamin content: its fibre they viewed with some apprehension. Anyway the advice of nutritionists had no impact on milling practice: when the extraction rate was raised it was because of the difficulties of shipping flour to the United Kingdom, not nutritional reasons. When the U-boat crisis passed in 1943, the rate was lowered again (Bull, 1978).

What professional nutritionists were doing from 1940 onwards, was adding thiamine, niacin, chalk and iron to flour, vitamin D to baby foods, and advocating vitamin $A$ and $C$ supplements to a country in which xeropthalmia and scurvy were virtually unknown. Do we now regard these actions as applied science, or were they the professionalization of existing enthusiasm?

\section{Nutritional policy in developing countries}

Post war nutrition has been dominated above all by the activities of the profession in eradicating non-existent protein deficiencies and other nutritional problems in developing countries (McLaren, 1975; Waterlow \& Payne, 1975). The story is too well known to need review here, but it stands out as a prime example of professionalization gone berserk. The lesson, however, is not simply one of infatuation with protein, it is more far sweeping than that.

When the doctors in the Warsaw Ghetto made their observations on 'Maladie de Famine' they were at least aware that the true cause of la Maladie was a German government bent on genocide, and this awareness colours everything they wrote. Ten years later the same disease was being described in Africa as an entity in itself, a nutritional disease with a nutritional cause. The idea that starvation was the result of poverty or exploitation, melted in the furnace of the professionalism of those who set themselves up as its arbiters.

\section{Conclusion}

This historical perspective has been caustic and severe. But the object has not been to deride the past, simply to change the present. I do not wish to prevent the growth in studies of nutrition at the molecular level, merely to prevent the growth of the idea that this will ultimately solve all nutritional problems (Neuberger, 1974). I do not wish to see nutrition become a social science, but the problems of nutrition, if not the science, do span the range from the combine harvester to the ribosome and can only be tackled if the social component of nutrition is studied (Rivers, 1975).

Above all, I do not wish nutritionists to abandon their dedication to the ideal of combatting disease. I wish merely for them to admit their failures, and approach the problems that now exist scientifically, rather than professionally.

At present the nutrition profession in the UK gives the impression of being a beached coelacanth. We wriggle and writhe, but we have an uncomfortable 
awareness we are out of our element. A dispassionate observer might also conclude that we are out of date. The old formula of untrammelled individualist researchers pursuing their enthusiams is breaking down in science in general. The diseases we feel we must tackle do not yield answers in the test-tube or the rat-cage. We have not yet adapted to the applied science we will have to undertake.

I began by regretting the professionalization of the nutrition as reflected in this Society. But it is a powerful body, and the members of this Society have a choice either to defend themselves by professionalizing, or to justify themselves by being of use to mankind. They will, I hope, choose the latter path.

\section{REFERENCES}

Baker, I. A., Cochrane, A. L. \& Elwood, P. C. (1977). Int. J. Epidemiol 6, 239.

British Medical Association (1933). Br. med. F. Supplement, November 25th, 1933.

British Medical Association (1939). Nutrition and the Public Health London: BMA.

British Medical Association (1950). Report of the Committee on Nutrition London: BMA.

Bull, N. L. (1978). The Nutritionists Role in U.K. Food Policy M.Sc. Thesis, University of London. Campbell, $H$. (1965). Changes in Mortality Trends in England and Wales $1931-1961$ Washington DC: US Dept. of Health, Education and Welfare.

Copping A. M. (1978). Proc. Nutr. Soc. 37, 105.

DeMaeyer, E. M. \& Bengoa, J. M. (1971). Amino Acid Fortification of Foods, [N. S. Scrimshaw and A. M. Altschul, editors]. California. Mass: MIT Press.

Illich, I. (1977). Disabling Professions. London: Marion Bower8.

James, W. P. T. (1978). Am. F. clin. Nutr. 31, 1419 .

McKeown, T. \& Lowe, A. (1966). An Introduction to Social Medicine. Oxford University Press.

McLaren, D. S. (1975). Lancet ii, 93.

Magee, H. E. (1946). Br. med. $\tilde{J}$. i, 472.

Neuberger, A. (1974). In Food and Nutrition Research. A report of an ARC/MRC Committee. London: HMSO.

Orr, J. B. (1935). Food, Health and Income. London: Macmillan \& Co.

Rivers, J. P. W. (1975). Nature, Lond. 253, 80.

Rivers, J. P. W. (1978). Concepts of Protein and Energy Requirements, 1780-1918 - DHMSA Thesis, Society of Apothecaries, London.

Singer, C. \& Underwood E. A. (1966). A Short History of Medicine, Oxford University Press. Walker, C. L. \& Church, M. A. (1978). F. Hum. Nutr. 32, 5.

Waterlow, J. C. \& Payne, P. R. (1975). Nature, Lond. 258, 113.

Woolf, B. (1946). Proc. Nutr. Soc. 5, 71. 